\title{
Effects of Aging on the Microstructure and Properties of 7075 Al Sheets
}

\author{
Zhongxin Zhao ${ }^{1}$, Ruoqing $\mathrm{Wu}^{2}$, Bo Wang ${ }^{3}$, Mingchu Huang ${ }^{2}$, Guopeng Lei ${ }^{1}$ and \\ Fenghua Luo 1,*(D) \\ 1 State Key Laboratory of Powder Metallurgy, Central South University, Changsha 410083, China; \\ zhongxinzhao@csu.edu.cn (Z.Z.); guopeng129@csu.edu.cn (G.L.) \\ 2 School of Materials Science and Engineering, Central South University, Changsha 410083, China; \\ wuruoqing@csu.edu.cn (R.W.); hmc1698@csu.edu.cn (M.H.) \\ 3 Sichuan Aerospace Changzheng Equipment Manufacturing Co. Ltd., Chengdu 600100, China; \\ wangbo18980769957@163.com \\ * Correspondence: fenghualuo@csu.edu.cn
}

Received: 12 August 2020; Accepted: 8 September 2020; Published: 10 September 2020

\begin{abstract}
The effects of one-step aging and double aging on the properties and microstructures of $7075 \mathrm{Al}$ sheets were studied via mechanical property testing, scanning electron microscopy, and transmission electron microscopy. The results indicated that with continued one-step aging, the tensile and yield strengths of the Al sheets first increased rapidly with an increase in the treatment time to $8 \mathrm{~h}$ and then increased slightly with a further increase in the treatment time to $10 \mathrm{~h}$. The tensile and yield strengths became constant after $16 \mathrm{~h}$ of treatment. The mechanical strength properties of the $\mathrm{Al}$ sheets peaked after $16 \mathrm{~h}$ of one-step aging. However, the double aging treatment provided better mechanical properties and working efficiency than the one-step aging treatment. The tensile strength and microhardness resulting from double aging were greater than those resulting from one-step aging by $5.87 \%$ and $8.71 \%$, respectively. Herein, we quantified the contribution ofvarious strengthening mechanisms.
\end{abstract}

Keywords: $7075 \mathrm{Al}$ alloy; aging behavior; precipitation strengthening; mechanical properties

\section{Introduction}

$\mathrm{Al}$ alloys (7075) are 7xxx series age-hardened $\mathrm{Al}$ alloys that are widely used in the aerospace and automotive fields owing to their low density, high strength, and moderate fatigue resistance [1-3]. Generally, the heat treatment of 7xxx series Al alloys includes solid solution and aging treatments, with aging treatments having a higher impact on performance. The microstructure of $\mathrm{Al}-\mathrm{Zn}-\mathrm{Mg}-\mathrm{Cu}$ alloys changes from a solid solution to Guinier-Preston (GP) zones, then to metastable precipitate $\eta^{\prime}$, and finally to the formation of the equilibrium phase $\eta$ during heat treatment $[4,5]$. Owing to the influence of aging treatment on the type, quantity, size, and distribution of precipitated phases in the alloy matrix, it determines the final strength, plasticity, and corrosion resistance of Al alloys [6]. Therefore, aging treatment has frequently been a research focus in studies considering the properties of Al alloys [7]. While the T6 condition can result in exceptional strength, the antistress corrosion resistance and impact property are poor [8,9]. Therefore, multistep aging processes have been developed in an attempt to control the structure and performance [10]. For example, double aging (DA) treatment can significantly reduce the aging time for the T6 properties of 7075 [11]. For alloys that display the evolution of a series of metastable phases, a low temperature at the first aging state will form a high density of GP zones in the matrix. These fine precipitates will assist the nucleation of $\eta^{\prime}$ phases during the second aging stage. At a high temperature with the formation of a more stable phase (such as $\eta^{\prime}$ phase), it is 
impossible to evolve GP zones again at a lower temperature from a thermodynamic perspective [12]. The influence of the $\mathrm{Al}-\mathrm{Zn}-\mathrm{Mg}-\mathrm{Cu}$ alloy composition on precipitation in various alloys, the evolution of mechanical performance after one-step and DA treatments, and some qualitative strengthening effects of precipitates have previously been studied $[13,14]$. Many different DA treatments have been researched; however, practical application parameters to improve production efficiency and save energy have not been optimized. In the present work, mechanical testing and microstructural characterization of $7075 \mathrm{Al}$ sheets subjected to one-step and DA treatments are discussed. Furthermore, the contribution of each strengthening mechanism was quantified with the goal of developing a deep understanding of the one-step aging and DA treatments of $7075 \mathrm{Al}$ sheets in isothermal aging.

\section{Material and Methods}

Table 1 lists the chemical composition of the $7075 \mathrm{Al}$ sheets. After casting, the $7075 \mathrm{Al}$ alloy was hot extruded (the extrusion temperature was $450{ }^{\circ} \mathrm{C}$ ) from the $\mathrm{Al}$ sheets (initial thickness of $13 \mathrm{~mm}$ ) with a reduction ratio of 8:1 to damage the as-cast microstructure; it was then subjected to a cold rolling process to obtain rolled sheets with a final thickness of $2 \mathrm{~mm}$. Before the heat treatment, the alloy sheets were cut into small samples with dimensions of $195 \mathrm{~mm} \times 25 \mathrm{~mm} \times 2 \mathrm{~mm}$. The samples were solid solutiontreated at $468^{\circ} \mathrm{C}$ in molten nitrates for $20 \mathrm{~min}$. They were then immediately quenched in water and cooled to room temperature. One-step aging was implemented at $140^{\circ} \mathrm{C}$ for $8,10,12,14$, and $16 \mathrm{~h}$ to obtain optimal properties. DA treatment was performed as follows: the samples were maintained at $120^{\circ} \mathrm{C}$ for $3 \mathrm{~h}$, maintained at $160^{\circ} \mathrm{C}$ for $3 \mathrm{~h}$, and finally air-cooled. Figure 1 summarizes the specific process.

Table 1. Chemical composition of the $7075 \mathrm{Al}$ alloy (mass fraction, \%).

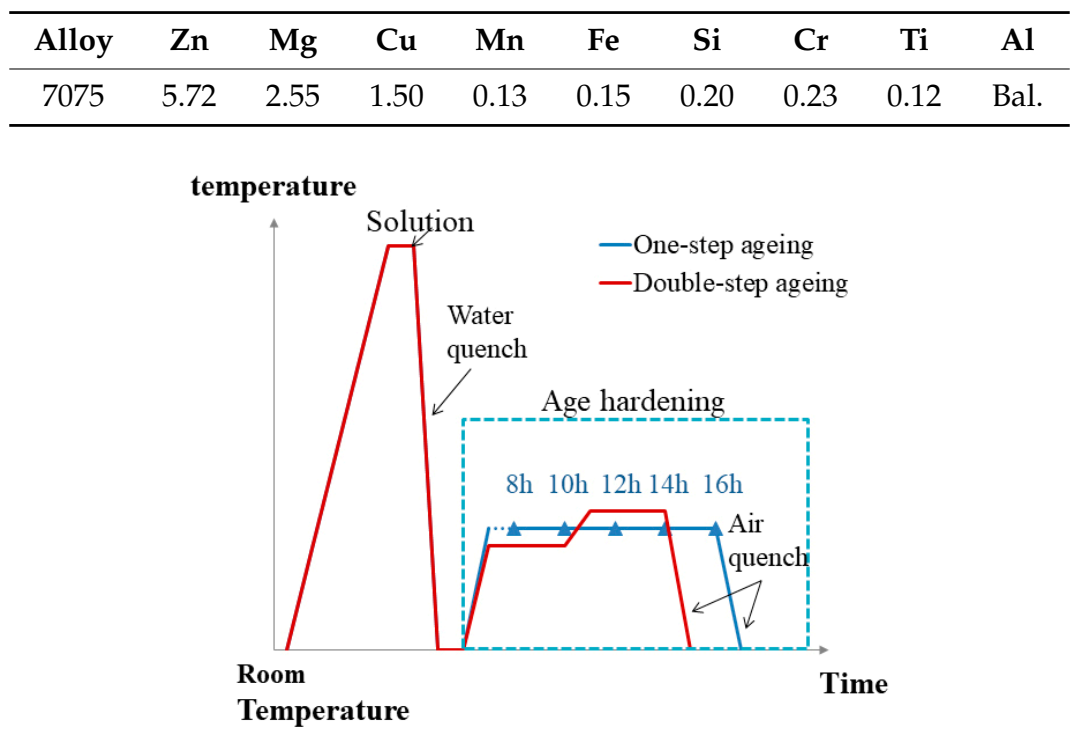

Figure 1. Schematic of the heat treatment process for $7075 \mathrm{Al}$ sheets. Blue curves indicate the one-step aging process at $140{ }^{\circ} \mathrm{C}$ for $8,10,12,14$, and $16 \mathrm{~h}$. Red curve denotes the double aging (DA) treatment at $120^{\circ} \mathrm{C}$ for $3 \mathrm{~h}$, followed by heating at $160^{\circ} \mathrm{C}$ for $3 \mathrm{~h}$.

After heat treatment, the corresponding mechanical properties and microstructure of the $7075 \mathrm{Al}$ sheets were tested and analyzed. The hardness of the samples was measured using a Shimadzu HMV-G21ST Vickers microhardness tester (Shimadzu, Kyoto, Japan); the load was HV 0.2 kgf with a keeping time of $10 \mathrm{~s}$, and the average of five hardness values for each sample was uniformly taken as the final result. After grinding and polishing, the Kelle etchant $(1 \mathrm{~mL} \mathrm{HF}, 1.5 \mathrm{~mL} \mathrm{HCl}, 2.5 \mathrm{~mL} \mathrm{HNO}$, and $95 \mathrm{~mL} \mathrm{H}_{2} \mathrm{O}$ ) was applied to corrode the surface of the samples. Metallographic images under different magnifications were obtained using a Leica DM 2700M metallographic microscope (Leica, Wetzlar, Germany). The tensile properties of the alloys were measured using an Instron 8802 electrohydraulic 
servo testing instrument (the tensile rate was $2 \mathrm{~mm} / \mathrm{min}$, Instron, Norwood, MA, USA), and the fracture morphologies were observed with a Nova Nano-SEM230 scanning electron microscope (FEI company, Hillsboro, OR, USA). Transmission samples were pre-ground to $50 \mu \mathrm{m}$, and a 30\% methanolic nitric solution was used at $-25^{\circ} \mathrm{C}$. A JEOL-2000F field transmission electron microscope (TEM, JEOL, Akashima, Tokyo, Japan) was used to observe the microstructures of the alloys and the number and size of the precipitated phases at the crystal and grain boundaries. In order to investigate the effect of precipitated phase strengthening on the tensile strength of the samples and the formation of dislocations, a few TEM foils were selected from the gage length section, which was located in the deformation area of the tensile sample.

\section{Results}

\subsection{Microstructure Analysis Results}

Figure 2 shows the optical microstructure of the $7075 \mathrm{Al}$ sheets under different heat treatment protocols. The morphologies were analyzed along the axis parallel to the rolling direction.
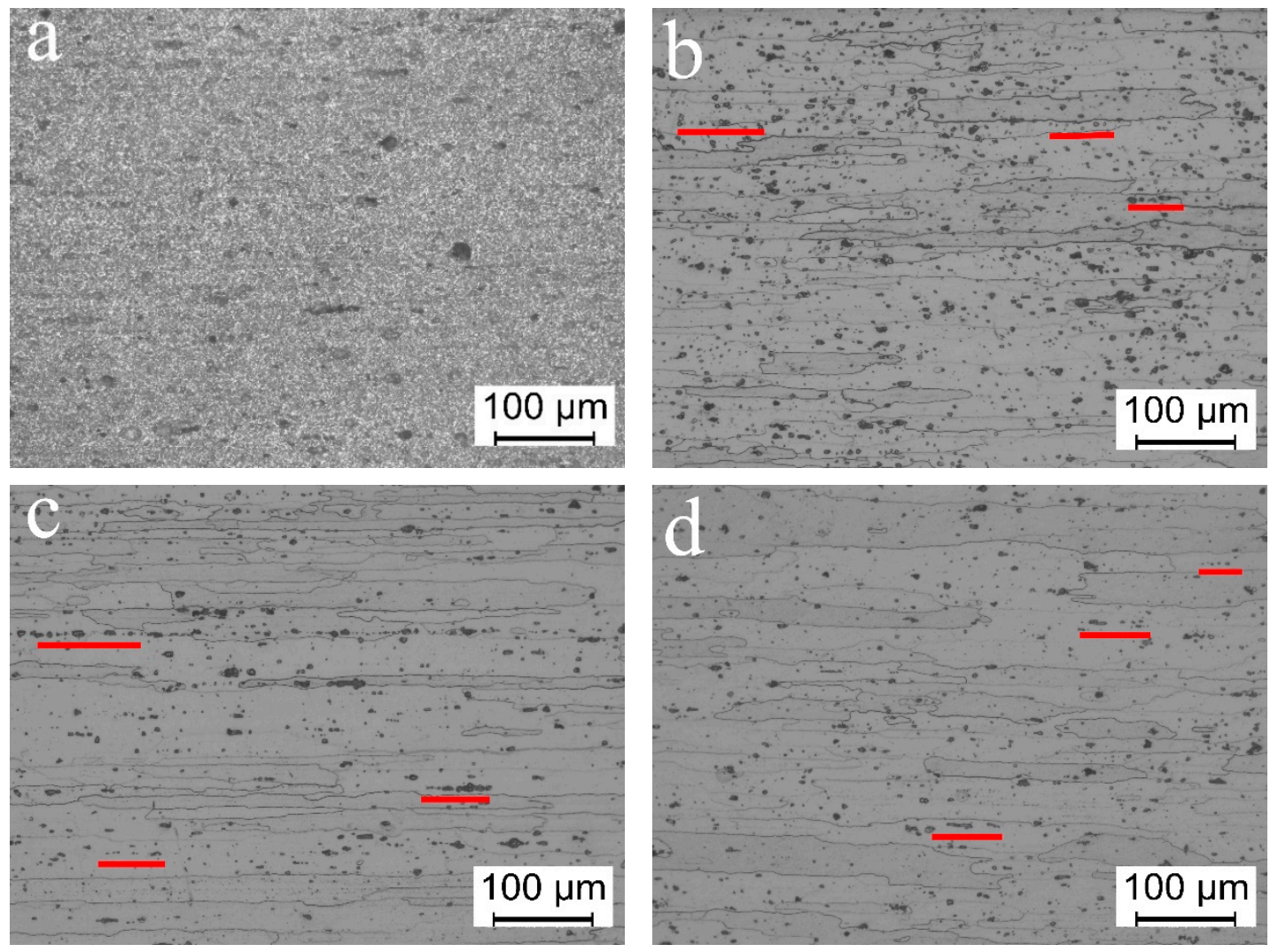

Figure 2. Longitudinal section optical microstructures of the $7075 \mathrm{Al}$ sheets subjected to an aging temperature of $140^{\circ} \mathrm{C}$ for different durations: (a) cold rolling state, (b) $8 \mathrm{~h},(\mathbf{c}) 16 \mathrm{~h}$ one-step aging, and (d) DA ( $3 \mathrm{~h}$ at $120^{\circ} \mathrm{C}$ and $3 \mathrm{~h}$ at $160{ }^{\circ} \mathrm{C}$ ) treatments; horizontal line represents the rolling direction.

Figure 2a shows the longitudinal section microstructure of the cold-rolled sheet along the rolling direction. It can be observed that the original cold rolling microstructure exhibited very fine metal fiber flow line structures. The metallographic structures of the samples with five different hold times at $140{ }^{\circ} \mathrm{C}$ were almost similar. The images of the samples with the hold times of 8 and $16 \mathrm{~h}$, which were used to analyze the subsequent results, are shown in Figure $2 b, c$, respectively. Figure $2 d$ shows the metallographic structure after DA treatment. As can be seen in Figure $2 b-d$, the base aluminum phases were coarse grains with distinct grain boundaries. These coarse grains exhibited significant rollingdirection oriented growth. In order to better describe the grain characteristics of the oriented 
growth grains, the maximum length and maximum width of each grain were measured by Image Plus Pro software (version 6.0, Media Cybernetics, Rockville, MD, USA), and then the average value was obtained. For example, the average length and width of the grains after one-step aging at $140{ }^{\circ} \mathrm{C}$ for $16 \mathrm{~h}$ were 281.1 and $31.7 \mu \mathrm{m}$, respectively, and the length and width of the grains in the DA sample were approximately 237.2 and $28.6 \mu \mathrm{m}$, respectively.

The grain characteristics of this oriented growth are related to the recrystallization nucleation and growth mechanism of the alloy during solid solution treatment. For 7075 alloy, a large amount of $\mathrm{MgZn} 2$

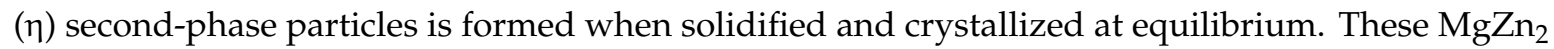
particles break during cold deformation and are aligned along the rolling direction. Figure $2 \mathrm{a}$ shows some fine granular compounds, most likely the $\mathrm{MgZn}_{2}$ phase. During the recrystallization process of the solid solution treatment, the grain boundary movement would be impeded. Because these particles will be distributed in a streamline, the resistance of grain growth in the thickness direction of the rolled plate is greater than that in the rolling direction, and the rate of recrystallized grain growth in the rolling direction is higher than in the transverse direction. Many black patches with the appearance of corrosion pits (highlighted by the short red line) can be observed in Figure 2b,c; these pits were oriented. These directional states are marked with red lines in the images. In the solidsolution process, though the $\mathrm{MgZn}_{2}$ phase should be completely dissolved, some of the particles do not dissolve completely owing to insufficient diffusion. Furthermore, even in the case of complete dissolution, element enrichment occurs at the original particle position. As a result, this position can be easily etched using a metallographic corrosion solution so as to show the corrosion pit. The number of corrosion pits in Figure 2c appears to be less than that in Figure 2b, which is due to the increase in aging time and the aging precipitation degree. From the perspective of thermodynamics, the energy state of the alloy decreases, thus increasing the resistance towards corrosion. From this perspective, Figure $2 \mathrm{~d}$ has fewer corrosion pits, indicating a lower energy state and complete aging precipitation.

\subsection{Hardness and Mechanical Properties}

The tensile properties of the $7075 \mathrm{Al}$ sheets after different one-step aging treatments at different times are illustrated in Figure 3. The 0h curve corresponds to the tensile properties of the sample subjected to the solid solution treatment at $468^{\circ} \mathrm{C}$ for $20 \mathrm{~min}$.

(a)

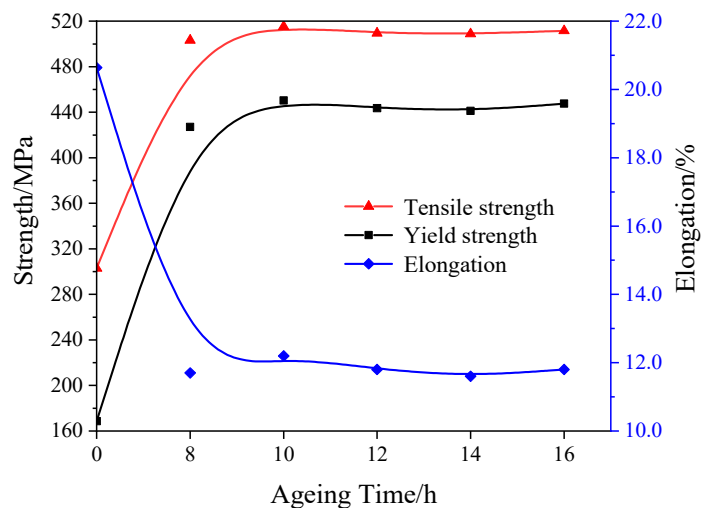

(b)

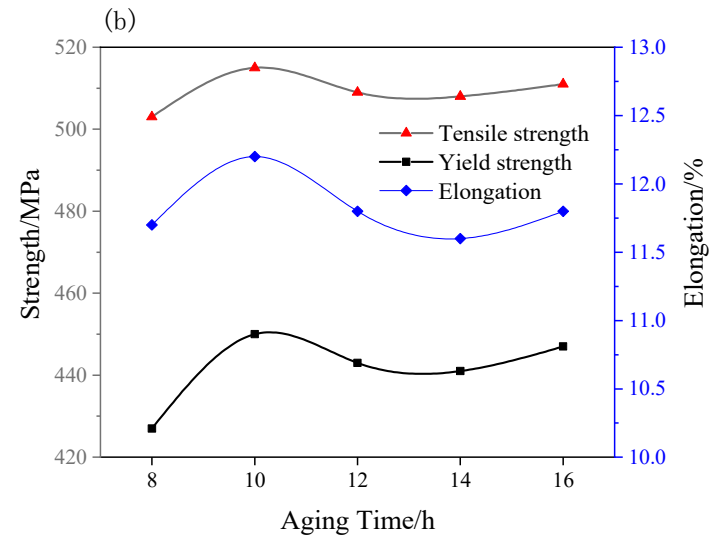

Figure 3. Tensile properties of the $7075 \mathrm{Al}$ sheets subjected to different one-step aging treatments. (a) The tensile properties during the whole process and $(\mathbf{b})$ a section of the process.

Figure 3a shows that the tensile strength of the samples first increased rapidly with an increase in the treatment time up to $8 \mathrm{~h}$ and then increased slightly with a further increase in the treatment time to $10 \mathrm{~h}$. The tensile strength became constant after $10 \mathrm{~h}$ of treatment time. The trend shown by the yield strength of the samples was consistent with that shown by the tensile strength and opposite to that shown by the elongation. Figure $3 b$ shows the magnified mechanical property curves of the samples over the aging treatment time range of 8-16 h. As can be observed from Figure $3 \mathrm{~b}$, the tensile strength 
first increased from 503.2 MPa to the peak value of $515 \mathrm{MPa}$ with an increase in the aging time from 8 to $10 \mathrm{~h}$ and then decreased slightly to $511.6 \mathrm{MPa}$ with a further increase in the aging time up to $16 \mathrm{~h}$.

In general, the aging sequence of $\mathrm{Al}-\mathrm{Zn}-\mathrm{Mg}-\mathrm{Cu}$ alloys isthe GP zones followed by the $\eta^{\prime}$ phase. At the initial stage of aging, the GP zones precipitate first, and the enhancement effect of the $\eta^{\prime}$ phase is more significant at the later stage. Therefore, it can be inferred that the strength peak in the early aging period of $10 \mathrm{~h}$ came from the strengthening of the GP zones. The aging time affected the coarsening and dissolution of the GP zones, $\eta^{\prime}$ phase fraction, and the source of the strength peak. It can be seen from Figure 3a that the change in the tensile property caused by aging time was not exceedingly significant. However, Figure $3 \mathrm{~b}$ shows that the elongation rate was also high when the strengthening peak appeared at the beginning of aging, which is a significantphenomenon and requires further exploration.

Table 2 lists the values of the tensile and microhardness properties of the $7075 \mathrm{Al}$ sheets at different heat treatment states.

Table 2. Mechanical properties of the $7075 \mathrm{Al}$ sheets subjected to different aging treatments.

\begin{tabular}{ccccc}
\hline Aging Time & $\begin{array}{c}\text { YS } \\
(\mathbf{M P a})\end{array}$ & $\begin{array}{c}\text { UTS } \\
\mathbf{( M P a )}\end{array}$ & $\begin{array}{c}\text { Elongation } \\
\mathbf{( \% )}\end{array}$ & $\begin{array}{c}\text { Microhardness } \\
\mathbf{( H V )}\end{array}$ \\
\hline $0 \mathrm{~h}$ & 168.7 & 302.9 & 20.6 & 36.4 \\
$8 \mathrm{~h}$ & 427.1 & 503.2 & 11.7 & 173.4 \\
$10 \mathrm{~h}$ & 450.3 & 515.3 & 12.2 & 179.8 \\
$12 \mathrm{~h}$ & 443.6 & 509.5 & 11.8 & 168.8 \\
$14 \mathrm{~h}$ & 441.2 & 508.8 & 11.6 & 170.4 \\
$16 \mathrm{~h}$ & 447.5 & 511.6 & 11.8 & 183.6 \\
DA treatment & 491.1 & 541.4 & 10.7 & 199.6 \\
\hline
\end{tabular}

YS is yield strength and UTS is ultimate tensile strength.

Ascan be observed in Table 2, in the one-step aging process and with an increase in the aging time, the hardness first increased, then decreased, reaching $183.6 \mathrm{HV}$ after $16 \mathrm{~h}$. However, with the DA treatment, the hardness obtained was higher and reached $199.6 \mathrm{HV}$. Overall, one-step aging at $140{ }^{\circ} \mathrm{C}$ for $16 \mathrm{~h}$ gave the best performance among the one-step processes. As expected, the DA treatment resulted in a significant increase in both the hardness and strength. The elongation after the DA treatment decreased only slightly compared to that after one-step aging.

\subsection{Morphology of Tensile Fracture}

Figure 4 shows the tensile fracture morphology of the $7075 \mathrm{Al}$ sheets after different aging conditions. Figure $4 \mathrm{a}-\mathrm{e}$ shows the fracture surfaces of the samples after undergoing a one-step aging treatment for $8,10,12,14$, and $16 \mathrm{~h}$, respectively. Figure $4 \mathrm{f}$ shows the same image for the sample subjected to a DA treatment.

The samples showed mixed ruptures with transgranular fractures and intergranular fractures. A number of tearing edges (indicated by red arrows), some small secondary particles, a number of fine dimples around the fractures (marked by the black circle A), and intergranular fractures (indicated by the black circle B), could be observed. Therefore, the fractures following the aging processes can be attributed to ductile failure. In addition, the fracture morphology of the samples depended on their aging conditions. As can be observed in Figure 4a, the sample aged for $8 \mathrm{~h}$ showed a large number of shear zones and dimples. From Figure $4 \mathrm{a}-\mathrm{e}$, it can be observed that with an increase in the one-step aging time from 8 to $16 \mathrm{~h}$, the density of the dimples and shear zones decreased, and the proportion of transgranular fractures also decreased significantly, while the intergranular fraction increased. This indicates that the fracture mode changed from transgranular dimple and transgranular shearing mixed fractures to intergranular fractures with an increase in the one-step aging time. As shown in Figure 4e,f, the DA treatment produced fewer large secondary phase particles 
compared to the $16 \mathrm{~h}$ one-step aging treatment. Moreover, the plasticity of the samples also decreased after the DA treatment [13]. The DA-treated samples showed fewer tearing edges and shear zones and larger dimples than the $16 \mathrm{~h}$ one-step aged sample. This indicated that the DA-treated $7075 \mathrm{Al}$ sheets showed mainly intergranular fractures like the one-step aged (16 h) sheets. However, the proportion of intergranular fractures was only slightly higher than that in the case of the one-step aged sheets.
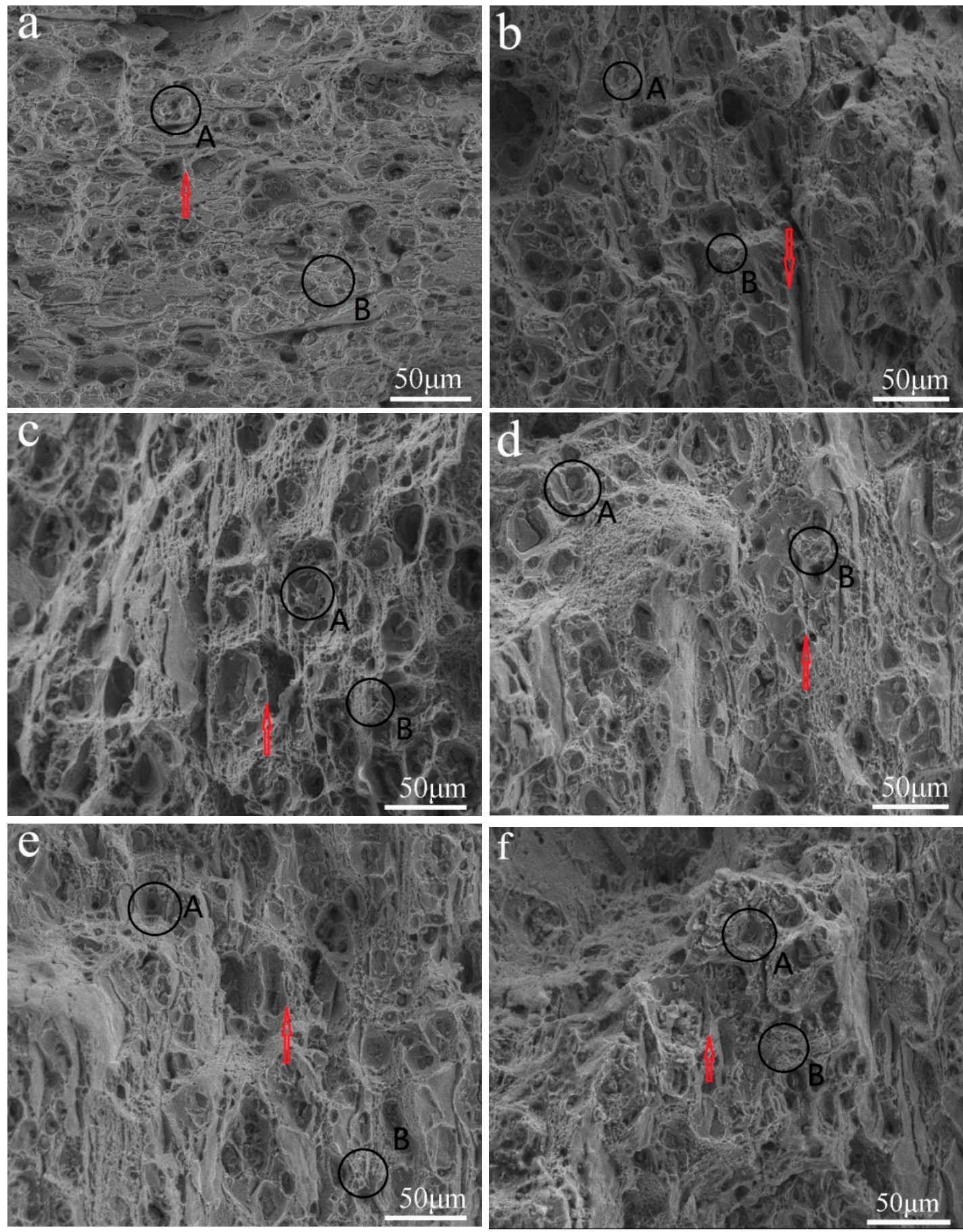

Figure 4. Tensile fracture morphologies of the $7075 \mathrm{Al}$ sheets subjected to one-step aging for various durations: (a) $8 \mathrm{~h},(\mathbf{b}) 10 \mathrm{~h},(\mathbf{c}) 12 \mathrm{~h},(\mathbf{d}) 14 \mathrm{~h}$, and (e) $16 \mathrm{~h}$ at $140{ }^{\circ} \mathrm{C}$; (f) DA treatment $\left(3 \mathrm{~h}\right.$ at $120^{\circ} \mathrm{C}$ and $3 \mathrm{~h}$ at $\left.160^{\circ} \mathrm{C}\right)$. 


\subsection{TEM Analysis}

Aging is an important heattreatment process used to improve the properties of $\mathrm{Al}$ alloys, and the type and distribution of the precipitated phases affect the performance of the material.

The samples with ideal mechanical performance were divided into two groups for further investigation: those subjected to one-step aging for $16 \mathrm{~h}$ and those subjected to the DA treatment. Figure $5 \mathrm{a}, \mathrm{b}$ shows the bright field (BF) TEM images and the corresponding selected area diffraction patterns (SADPs) of the one-step and the DA-treated samples along the $[001]_{\mathrm{Al}}$ zone axis. In the $[001]_{\mathrm{Al}}$ zone axis, two types of $\eta^{\prime}$ structures, namely, plate-like and round-shaped, were identified.
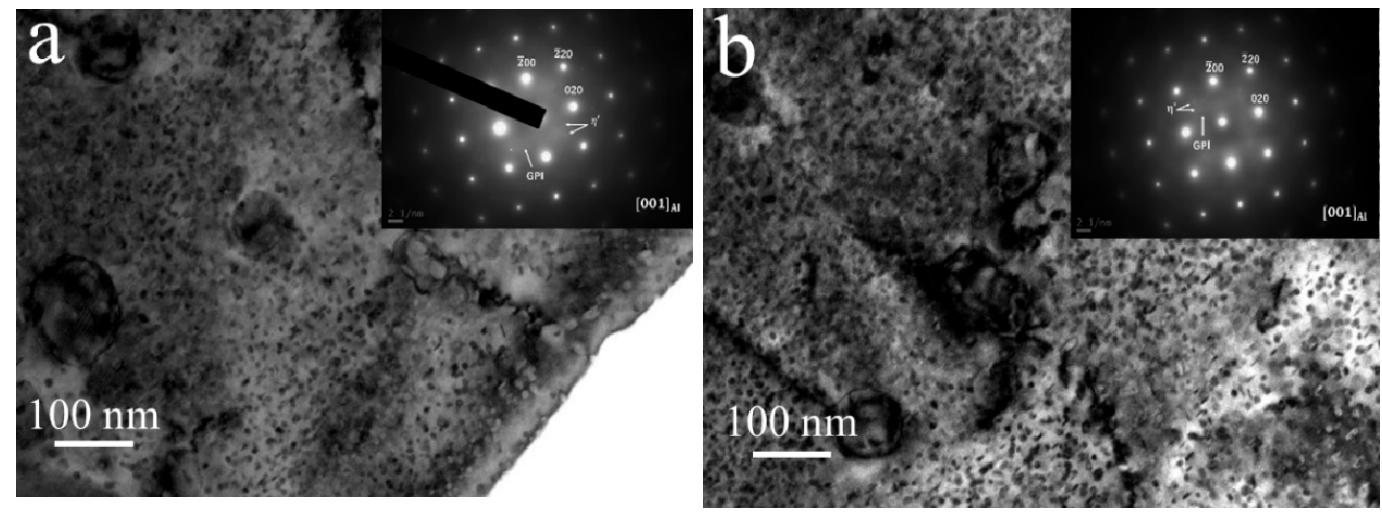

Figure 5. Bright field (BF) TEM images and diffraction patterns of the $7075 \mathrm{Al}$ sheets in the $[001]_{\mathrm{Al}}$ zone axis: (a) one-step aging for $16 \mathrm{~h}$ at $140{ }^{\circ} \mathrm{C}$ and (b) DA treatment $\left(3 \mathrm{~h}\right.$ at $120^{\circ} \mathrm{C}$ and $3 \mathrm{~h}$ at $160{ }^{\circ} \mathrm{C}$ ).

As shown in Figure $5 a, b$, the precipitation density of the DA treatment sample was greater than that of the one-step aged sample; however, the sizes of the precipitates in the two cases were similar. An analysis of the diffraction images identified diffraction spots for the $\eta^{\prime}$ phase and the GP zones, where the GP zone diffraction spots are located at $1 / 3\{422\}$ and the diffraction spots of the $\eta^{\prime}$ phase are located at $1 / 3$ and $2 / 3$ of the $\{220\}$ plane [13]. Figure $5 a, b$ shows that the second-phase diffraction spots exhibited after DA treatment were brighter than those after one-step aging, while the diffraction spots in the GP zone were dimmer, indicating an increase in the number of precipitated phases and a decrease in the number of GP zones formed in the early stages of aging. The fine and uniformly distributed $\eta^{\prime}$ precipitates in the matrix are in a semicoherent relationship with the matrix and can hinder the movement of dislocations, thus increasing the strength of the alloys [15].

In the $7075 \mathrm{Al}$ sheets, TEM foils were selected from the gage deformed area of the tensile sample to analyze the strengthening of the dislocations. Tangles or networks of dislocations were formed after the aging process (indicated by red arrows in Figure $6 a, b)$. Moreover, the dislocation density of the DA treatment sample was higher than that of the one-step aged sample.
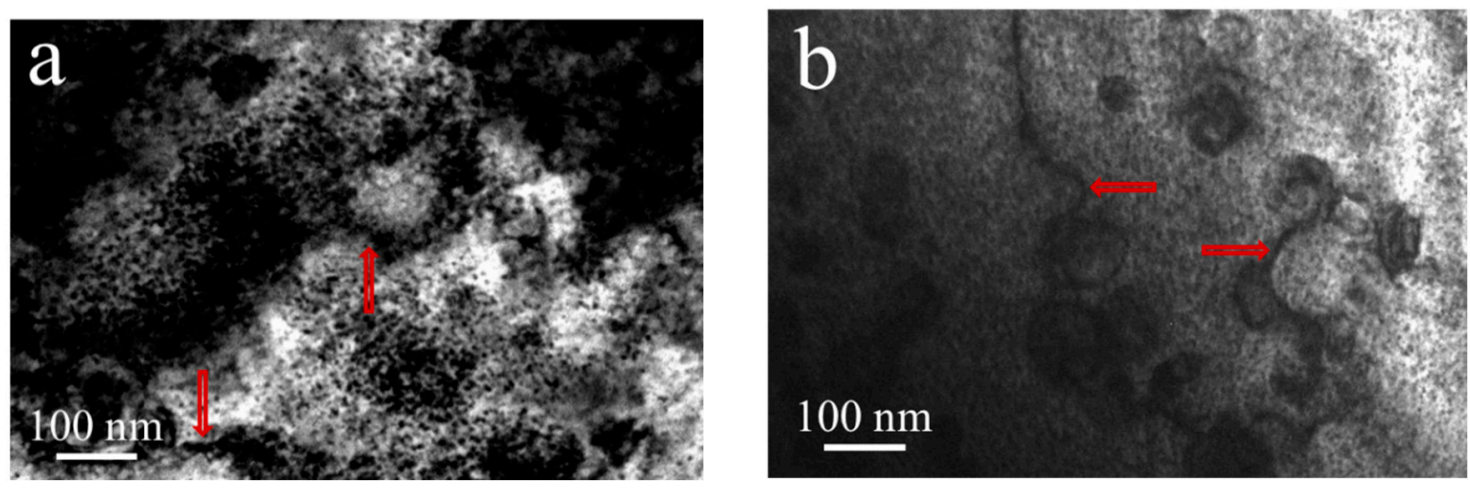

Figure 6. Microstructures of the dislocations of the $7075 \mathrm{Al}$ sheets along the $[001]_{\mathrm{Al}}$ zone axis: (a) one-step aging for $16 \mathrm{~h}$ at $140{ }^{\circ} \mathrm{C}$ and (b) DA treatment $\left(3 \mathrm{~h}\right.$ at $120^{\circ} \mathrm{C}$ and $3 \mathrm{~h}$ at $\left.160{ }^{\circ} \mathrm{C}\right)$. 
With the parameters of the one-step and DA treatment grains (as shown in Figure 2 and Section 3.1), the strengthening effect of the grains size was found to be less than $10 \mathrm{MPa}$. The calculation was carried out according to Equation (4), as discussed further on. However, under experimental conditions, the strength of the sample was high, indicating that the subgrains played an important role in the strengthening mechanism. The average length and width of the subgrains after one-step aging were 1.2 and $0.5 \mu \mathrm{m}$, respectively. The length and width of the elongated subgrains in the DA treatment sample were $\sim 1.0$ and $\sim 0.4 \mu \mathrm{m}$, respectively, according to the standard [16]. However, it is essential to explore the characteristics of precipitation, precipitation size ranges, average size of the precipitate, etc. Thus, in view of the limited methodology available, the quantitative details of the precipitates were gathered with Image Plus Pro (IPP). Considering the structure of the precipitates, the length of the long axis could be treated as the diameter, and the sizes of the elliptical precipitations were treated in the same manner. Figure 7 presents the distribution of different diameters of $\eta^{\prime}$ (the uncertainty in the diameter is $1 \mathrm{~nm}$ ), and it should be noted that extremely small or large particles were ignored.
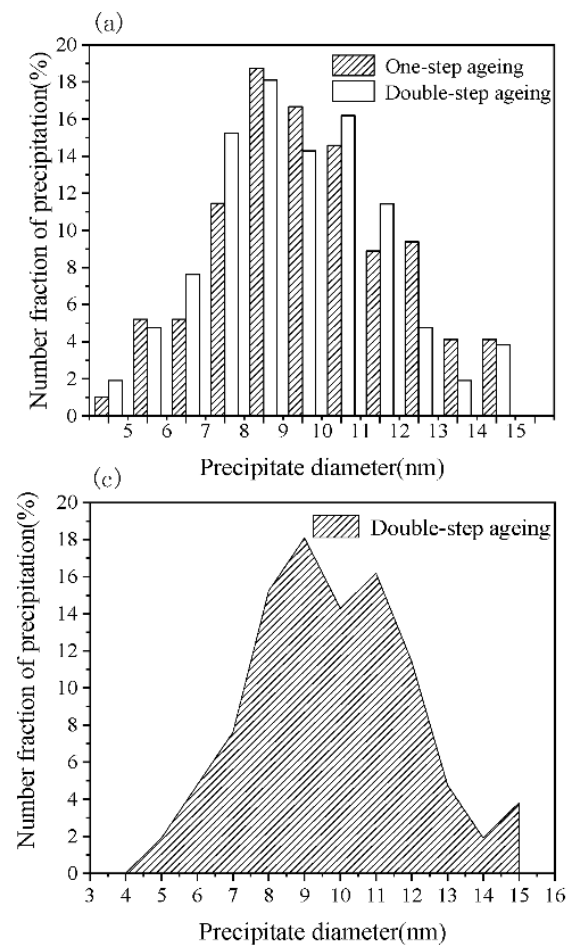

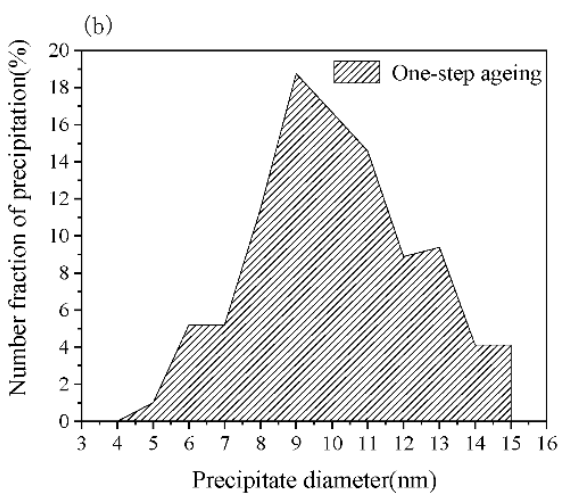

Figure 7. Precipitate size distributions: (a) histogram (the uncertainty is $1 \mathrm{~nm}$ ) and the shadow region diagram of (b) one-step aging for $16 \mathrm{~h}$ at $140{ }^{\circ} \mathrm{C}$ and (c) DA treatment $\left(3 \mathrm{~h}\right.$ at $120^{\circ} \mathrm{C}$ and $3 \mathrm{~h}$ at $\left.160{ }^{\circ} \mathrm{C}\right)$.

According to statistical analysis, the size of the precipitates was concentrated within the range of 7-11 nm for both the one-step and two-step aging processes (shown in Figure 7a). To minimize the error, a 95\% confidence level was set according to Equation (1):

$$
P\left\{D_{1}<D_{x}<D_{2}\right\}=1-a
$$

where $P$ represents the probability that some precipitate diameter, $D_{x}$, will be between $D_{1}(\mathrm{~min})$ and $D_{2}$ (max) and it amounts to $95 \%$ (with $5 \%$ probability of a type I error, i.e., $100-5=95 \%$ ) with a value of $D_{1}$ and $D_{2}$ of 5 and $14 \mathrm{~nm}$, respectively. The average size of the precipitates was calculated from Figure $7 b, c$ with Equation (2):

$$
D_{\text {mean }}=\frac{1}{n} \sum_{x=1}^{n} D_{x} f_{x}
$$


where $f_{x}$ is the corresponding fraction percent of the precipitates. The resulting average diameter of the precipitates after one-step aging was $9.05 \mathrm{~nm}$. Applying the same method, the average precipitate size after two-step aging was $8.72 \mathrm{~nm}$. The method of convergent beam diffraction can be used to confirm the sample thickness [17]. To reduce the error of convergence, the reliable thickness should exceed $50 \mathrm{~nm}$; however, considering the high density of precipitates, the thickness should be less than this value [17]. Thus, the maximum sample thickness of $50 \mathrm{~nm}$ was adopted for one-step and two-step aging processes in the following analyses. On the basis of some helpful hypotheses proposed by other researchers [18], the precipitate volume of the one-step aged samples was calculated using Equation (3):

$$
V_{p}=V_{\text {sphere }}+2 V_{\text {platelet }}-V_{\text {cor }}
$$

where $V_{\text {sphere }}$ is the volume of observed round particles and $V_{\text {sphere }}=4 / 3 \pi R_{s}{ }^{3}, V_{\text {platelet }}$ is the volume of the observed platelets and $V_{\text {plate }}=\pi / 4 T D^{2}$ ( $T$ is the thickness of the precipitate, and $T \approx 0.38 D$ ) [18], and $V_{c o r}$ is the volume of the platelets with round precipitates and $V_{\text {cor }}=4 / 3 \pi R_{\text {mean }}{ }^{3}$. The volume fraction is $\varphi=V_{p} / V$, where $V$ represented the volume of the sample, which was replaced by the area of the TEM images multiplied by the sample thickness. The result of the volume fraction of the precipitations was $5.25 \pm 0.3 \%$ and $6.57 \pm 0.3 \%$ for the one-step aging at $140{ }^{\circ} \mathrm{C}$ for $16 \mathrm{~h}$ and two-step aging treatments, respectively.

\section{Discussion}

In an $\mathrm{Al}$ alloy, including the extruded $\mathrm{Al} 7 \mathrm{xxx}$ series alloys, several types of strengthening mechanisms are at play, including solid solution strengthening, precipitation strengthening, dislocation strengthening, and grain boundary strengthening [19]. In this work, different aging conditions were studied and the Hall-Petch Equation (4) was used to analyze the grain boundaries [20]:

$$
\Delta \sigma_{H P}=\sigma_{f}+k_{i} d^{-m}
$$

Here, $\Delta \sigma_{H P}$ is the increment in yield strength, $\sigma_{f}$ is the yield strength for pure $\mathrm{Al}$ at the initial grain state (approximate value $16 \mathrm{MPa}$ [21]), $k_{i}$ is the Hall-Petch constant $\left(0.065 \mathrm{MPa} \cdot \mathrm{m}^{-\frac{1}{2}}\right.$ for pure aluminum) [22]), $d$ is the typical average subgrain size (typically 1.39 and $1.08 \mu \mathrm{m}$ ), and $m$ is an index for grain boundary strengthening (typical value of 1/2). Table 3 lists the results obtained using the corresponding equations.

\begin{tabular}{|c|c|c|}
\hline Strengthening Increment, $\mathrm{MPa}$ & $\begin{array}{l}\text { One-Step Aging } \\
(16 \mathrm{~h})\end{array}$ & $\begin{array}{c}\text { DA Treatment } \\
\left(3 \mathrm{~h} \text { at } 120^{\circ} \mathrm{C} \text { and } 3 \mathrm{~h} \text { at } 160^{\circ} \mathrm{C}\right)\end{array}$ \\
\hline Grain boundary strengthening, $\Delta \sigma_{H P}$ & 71.1 & 78.6 \\
\hline Dislocation strengthening, $\Delta \sigma_{d}$ & 72.0 & 87.3 \\
\hline Precipitation strengthening, $\Delta \sigma_{p p t}$ & 83.4 & 96.1 \\
\hline Yield strengthening Increment, $\Delta \sigma_{\text {tot }}$ & 401.6 & 468.2 \\
\hline
\end{tabular}

Table 3. Strengthening increment by different strengthening mechanisms.

Dislocation strengthening follows Taylor's relationship as described in Equation (5):

$$
\Delta \sigma_{d}=\frac{B G b}{L}
$$

Here, $B$ is 0.2 for FCC metals, $G$ is the shear modulus and is $26.9 \mathrm{GPa}$ for $\mathrm{Al}-\mathrm{Zn}-\mathrm{Mg}-\mathrm{Cu}$ alloys, $b$ is the Burgers vector and is $0.284 \mathrm{~nm}$, and $L$ is the average interparticle spacing as described in Equation (6) [23]:

$$
L=r_{p}\left\{(2 \pi / 3 f)^{1 / 2}-(8 / 3)^{1 / 2}\right\}
$$


In Equation (6), $r_{p}$ represents the radius of $\eta^{\prime}$ with values $(4.53$ and $4.36 \mathrm{~nm})$ as discussed in Section 3.4, and $f$ is 0.0525 and 0.0657 for the one-step aging and DA treatment processes, respectively. Thus, for one-step aging, $L=4.53 \times\left\{(2 \times 3.14 / 3 \times 0.0525)^{1 / 2}-(8 / 3)^{1 / 2}\right\}$ and its value was approximately $21.21 \mathrm{~nm}$. Therefore, the expression of $\Delta \sigma_{d}$ is $\left(0.2 \times 26.9 \times 10^{3} \times 0.284\right) / 21.21$ and its value was approximately $71.1 \mathrm{MPa}$. A similar calculation procedure was applied to the dislocation strengthening of double aging and the following strengthening mechanisms, and it did not list specific expressions.

Precipitation strengthening can be calculated using Equation (7) [24]:

$$
\Delta \sigma_{p p t}=A \frac{1}{\delta \sqrt{3}(\sqrt{\pi / 6 f}-\sqrt{2 / 3})} \ln \frac{\sqrt{2} \delta}{r_{0}}
$$

where $A$ is a constant equaling $0.85 G b / 2 \pi(1-v)^{1 / 2}, v$ represents the Poisson ratio value of 0.3 for $\mathrm{Al}$ alloys, $\delta$ is the diameter for the round precipitates (with values 9.05 and $8.72 \mathrm{~nm}$ as discussed in Section 3.4), and $r_{0}$ represents the core radius of the dislocation (ca. $0.6 \mathrm{~nm}$ ) [25].

Solid solution strengthening also plays a part in the overall strengthening process. However, as some $\mathrm{Mg}$ and $\mathrm{Zn}$ species form precipitates in a solid solution, the contribution of the solid solution atoms will be less than that under ideal conditions. Therefore, we did not consider solid solution strengthening here.

The total yield strength results from the different mechanisms can be summarized as follows [26]:

$$
\sigma_{t o t}=\Delta \sigma_{H P}+M\left\{\left(\Delta \sigma_{d}^{2}+\Delta \sigma_{p p t}^{2}\right)^{\frac{1}{2}}\right\}
$$

where $M$ is the Taylor factor equal to 3 [27]. The total yield strength values of the samples are listed in Table 3.

The experimental yield strengths (Table 2) of the $16 \mathrm{~h}$ one-step aged and DA-treated samples were higher than their calculated yield strengths (45.9 and 22.9 MPa, respectively). This may result from lattice strengthening, solid solution strengthening, modulus strengthening, and/or stacking fault strengthening. Moreover, it is possible that precipitation strength plays a more significant role than dislocation interaction because the formation of precipitate leads to an increase in the number of subgrains and hinders further plastic deformation.

It is interesting that this work is similar to a study by S.V. Emani [11], which involved DA treatment of 7075 extrusions. In that paper, aging at $121^{\circ} \mathrm{C}$ for $55 \mathrm{~min}$ and then aging at $177^{\circ} \mathrm{C}$ for $55 \mathrm{~min}$ resulted in a tensile strength of $548 \mathrm{MPa}$, yield strength of $417 \mathrm{MPa}$, elongation of $16 \%$, and microhardness less than $191 \mathrm{HV}$. In this study, the rolling sheets showed a tensile strength of $541.4 \mathrm{MPa}$, a yield strength of $491.1 \mathrm{MPa}$, an elongation of $10.7 \%$, and a microhardness of $199.6 \mathrm{HV}$ after DA treatment. The tensile strength of these sheets was slightly lower than that of the 7075 extrusions because of the extrusion effect. The aging process used in this study was for a longer duration; however, the aging temperature was lower than those reported previously. Owing to the fact that DA treatment parameters have not been optimized and widely accepted, the new double aging process was implemented along with different one-step aging treatments, and the results were studied and compared. In summary, it should be noted that the DA treatment applied in this study markedly reduced the procedure from 16 to $6 \mathrm{~h}$. The microhardness and tensile strength both increased beyond that of conventional one-step aging, and the ductility dropped slightly. This method can save energy and improve the production efficiency in practical industrial production. The role of various strengthening mechanisms on the mechanical behavior was also analyzed and the results summarized.

\section{Conclusions}

In this work, we studied different aging treatments for $7075 \mathrm{Al}$ sheets. microstructures, we gained insight into several strengthening mechanisms. By studying the performance and microstructure details can be summarized as follows: 
1. During one-step aging, the strength and hardness of the $7075 \mathrm{Al}$ sheet first increased, then decreased. The tensile properties peaked after aging for $10 \mathrm{~h}$; the tensile strength and microhardness were $515.3 \mathrm{MPa}$ and $179.8 \mathrm{HV}$, respectively. Double aging of the $\mathrm{Al}$ sheet gave better mechanical properties than one-step aging; the tensile strength and microhardness were increased by $33.5 \mathrm{MPa}$ and $12.2 \mathrm{HV}$, respectively.

2. The microstructural analysis showed that the samples subjected to double aging had higher dislocation and precipitation densities. Double aging resulted in the formation of a large number of distributed $\eta^{\prime}$ phases and GP zones in the matrix within a short period of time. The strength and working efficiency of the sheets improved significantly.

3. Precipitation had a significant influence on the $7075 \mathrm{Al}$ sheets compared to dislocation.

Author Contributions: Conceptualization, Z.Z. and F.L.; methodology, M.H.; software, G.L.; validation, Z.Z. and B.W.; formal analysis, M.H.; investigation, Z.Z. and G.L.; resources, B.W.; data curation, R.W.; writing—original draft preparation, Z.Z.; writing—review and editing, F.L.; visualization, R.W.; supervision, F.L.; project administration, F.L.; funding acquisition, Z.Z. All authors have read and agreed to the published version of the manuscript.

Funding: This research was funded by the Fundamental Research Funds for the Central Universities of Central South University, grant number 2019zzts229.

Conflicts of Interest: The authors declare that they have no conflict of interest.

\section{References}

1. Ferragut, R.; Somoza, A.; Tolley, A. Microstructural evolution of 7012 alloy during the early stages of artificial ageing. Acta Mater. 1999, 47, 4355-4364. [CrossRef]

2. Williams, J.C.; Starke, E.A., Jr. Progress in structural materials for aerospace systems. Acta Mater. 2003, 51, 5775-5799. [CrossRef]

3. Lei, C.; Li, H.; Fu, J.; Bian, T.J.; Zheng, G.W. Non-isothermal creep aging behaviors of an Al-Zn-Mg-Cu alloy. Mater. Charact. 2018, 144, 431-439. [CrossRef]

4. Berg, L.K.; Gjønnes, J.; Hansen, V.; Li, X.Z.; Knutson-Wedel, M.; Waterloo, G.; Schryvers, D.; Wallenberg, L.R. GP-zones in Al-Zn-Mg alloys and their role in artificial aging. Acta Mater. 2001, 49, 3443-3451. [CrossRef]

5. Liu, M.; Klobes, B.; Maier, K. On the age-hardening of an Al-Zn-Mg-Cu alloy: A vacancy perspective. Scr. Mater. 2011, 64, 21-24. [CrossRef]

6. Liu, L.L.; Pan, Q.L.; Wang, X.D.; Xiong, S.W. The effects of aging treatments on mechanical property and corrosion behavior of spray formed 7055 aluminum alloy. J. Alloys Compd. 2018, 735, 261-276. [CrossRef]

7. Jiang, J.T.; Xiao, W.Q.; Yang, L.; Shao, W.Z.; Yuan, S.J.; Zhen, L. Ageing behavior and stress corrosion cracking resistance of a non-isothermally aged Al-Zn-Mg-Cu alloy. Mater. Sci. Eng. A 2014, 605, 167-175. [CrossRef]

8. Sha, G.; Cerezo, A. Early-stage precipitation in Al-Zn-Mg-Cu (7050). Acta Mater. 2004, 52, 4503-4516. [CrossRef]

9. Khan, M.A.; Wang, Y.W.; Mohamed, A.A.; Malik, A.; Nazeer, F.; Yasin, G.; Yiawei, B.; Zhang, H. Microstructure and mechanical properties of an Al-Zn-Cu-Mg alloy processed by hot forming processes followed by heat treatments. Mater. Charact. 2019, 157, 109901. [CrossRef]

10. Engdahl, T.; Hansen, V.; Warren, P.J.; Stiller, K. Investigation of fine scale precipitates in Al-Zn-Mg alloys after various heat treatments. Mater. Sci. Eng. A 2002, 327, 59-64. [CrossRef]

11. Emani, S.V.; Benedyk, J.; Nash, P.; Chen, D. Double aging and thermomechanical heat treatment of AA7075 aluminum alloy extrusions. Mater. Sci. 2009, 44, 6384-6391. [CrossRef]

12. Massalski, T.B. The Al-Cu (Aluminum-Copper) system. Bull. Alloy Phase Diagr. 1980, 1, 27-33. [CrossRef]

13. Shercliff, H.R.; Ashby, M.F. A process model for age hardening aluminium alloys-I: The model. Acta Mater. 1990, 38, 1789-1802. [CrossRef]

14. Ogura, T.; Hirose, A.; Sato, T. Effect of PFZ and Grain Boundary Precipitate on Mechanical Properties and Fracture Morphologies in Al-Zn-Mg (Ag) Alloys. In Proceedings of the 6th International Conference on Processing and Manufacturing of Advanced Materials (THERMEC) Congress, Berlin, Germany, 25-29 August 2009. 
15. Jiang, X.J.; Noble, B.; Holme, B.; Waterloo, G.; Tafto, J. Differential scanning calorimetry and electron diffraction investigation on low-temperature aging in Al-Zn-Mg alloys. Metall. Mater. Trans. A 2000, 31, 339-348. [CrossRef]

16. ASTM International. ASTM E 112-13, Standard Test Methods for Determining Average Grain Size; ASTM: West Conshohocken, PA, USA, 2013.

17. Kelly, P.M.; Jostsons, A.; Blake, R.G.; Napier, J.G. The determination of foil thickness by scanning transmission electron microscopy. Phys. Status Solidi A 1975, 31, 771-780. [CrossRef]

18. Dumont, M.; Lefebvre, M.; Doisneau-Cottignies, B.; Deschamps, A. Characterisation of the composition and volume fraction of $\eta^{\prime}$ and $\eta$ precipitates in an $\mathrm{Al}-\mathrm{Zn}-\mathrm{Mg}$ alloy by a combination of atom probe; small-angle X-ray scattering and transmission electron microscopy. Acta Mater. 2005, 53, 2881-2892. [CrossRef]

19. Williamson, G.; Hall, W.H. X-ray line broadening from filed aluminum and wolfram. Acta Metall. 1953, 1, 22-31. [CrossRef]

20. Sylwestrowicz, W.; Hall, E.O. The deformation and ageing of mild steel: III Discussion of results. Proc. Phys. Soc. B 1951, 64, 747-753. [CrossRef]

21. Hornbogen, E.; Starke, E.A., Jr. Overview no. 102 Theory assisted design of high strength low aluminium. Acta Metall. Mater. 1993, 41,1-16. [CrossRef]

22. Embury, J.D.; Lloyd, D.J.; Ramachandran, T.R. Aluminum Alloys-Contemporary Research and Applications: Treatise on Materials Science Technology; Academic Press: Boston, MA, USA, 1989.

23. Martin, J.W. Micromechanisms in Particle-Strengthened Alloys; Cambridge University Press: Cambridge, UK, 1980.

24. Kelly, P.M. The effect of particle shape on dispersion hardening. Scr. Metall. 1972, 6, 647-656. [CrossRef]

25. Harkness, S.D.; Hren, J.J. An investigation of strengthening by spherical coherent G.P. Zones. Met. Trans. 1970, 1, 43-49.

26. Dixit, M.; Mishra, R.S.; Sankaran, K.K. Structure-property correlations in Al 7050 and Al 7055 high-strength aluminum alloys. Mater. Sci. Eng. A 2007, 478, 163-172. [CrossRef]

27. Totten, G.E.; MacKenzie, D.S. Handbook of Aluminum. In Physical Metallurgy and Processes; Marcel Dekker: New York, NY, USA, 2003; Available online: https://www.routledge.com/Handbook-of-Aluminum-Vol-1Physical-Metallurgy-and-Processes/Totten-MacKenzie/p/book/9780824704940 (accessed on 26 March 2003).

(C) 2020 by the authors. Licensee MDPI, Basel, Switzerland. This article is an open access article distributed under the terms and conditions of the Creative Commons Attribution (CC BY) license (http://creativecommons.org/licenses/by/4.0/). 